\title{
Healthcare-associated (HA) bloodstream infections (BSI) secondary top surgical site infections: surveillance program across Quebec hospitals (2007 to 2010)
}

\author{
V Blouin ${ }^{1 *}$, E Fortin ${ }^{2}$, I Rocher ${ }^{3}$, A Fortin ${ }^{2}$, C Tremblay ${ }^{4}$, C Frenette ${ }^{1}$, C Quach 1 , SPIN Network \\ From International Conference on Prevention \& Infection Control (ICPIC 2011) \\ Geneva, Switzerland. 29 June - 2 July 2011
}

\section{Introduction / objectives}

To describe HA-BSI secondary to surgical site infections (SSI) in Quebec hospitals.

\section{Methods}

Acute care centers with $\geq 1000$ admissions/year were invited to participate voluntarily and declare via a web portal all HA-BSIs secondary to a SSI between 2007 and 2010.The surveillance program also included outpatients and paediatric patients.

\section{Results}

56 of the 89 eligible centers participated (67\% of shortterm hospital beds), $64 \%$ of those beds were in teaching hospitals. Of the 7709 episodes of HA-BSIs, 874 (11\%) were secondary to a SSI. Gastrointestinal surgeries were, by far, the leading cause of BSIs (244 $28 \%)$ followed by cardiac surgery $(132-15 \%)$, and orthopaedic surgery $(98-11 \%)$. Implants were present in 25 cases (19\%). The majority of SSIs (496-57\%) were organ space infections. S. aureus was the organism most often isolated in 28\% (274), followed by E. coli in 13\% (130) of patients. Overall, $79 \%$ of patients were admitted on a general/specialised ward upon onset, compared to $15 \%$ in ICU, and $6 \%$ in ambulatory care. The mean time to infection was 21 days with a median of 10 days (median time to infection for cardiac compared to gastrointestinal surgery: 11 and 8 days respectively). $75 \%$ of BSIs occurred in teaching hospitals.

\section{Conclusion}

The Quebec surveillance program for HA-BSIs is a convenient way to survey the most severe SSIs, awaiting the development of a complete SSI surveillance program. Further analyses are needed to better understand the correlation between this targeted program and a complete SSI surveillance program.

\section{Disclosure of interest}

None declared.

\section{Author details}

${ }^{1}$ McGill University, Montreal, Canada. ${ }^{2} \mathrm{INSPQ}$, Quebec, Canada. ${ }^{3} \mathrm{INSPQ}$, Montreal, Canada. ${ }^{4} \mathrm{CHUQ}$, Quebec, Canada.

Published: 29 June 2011

\section{doi:10.1186/1753-6561-5-S6-P63}

Cite this article as: Blouin et al:: Healthcare-associated (HA) bloodstream infections (BSI) secondary top surgical site infections: surveillance program across Quebec hospitals (2007 to 2010). BMC Proceedings 2011 5(Suppl 6):P63.

${ }^{1}$ McGill University, Montreal, Canada

Full list of author information is available at the end of the article

(c) 2011 Blouin et al; licensee BioMed Central Ltd. This is an open access article distributed under the terms of the Creative Commons 